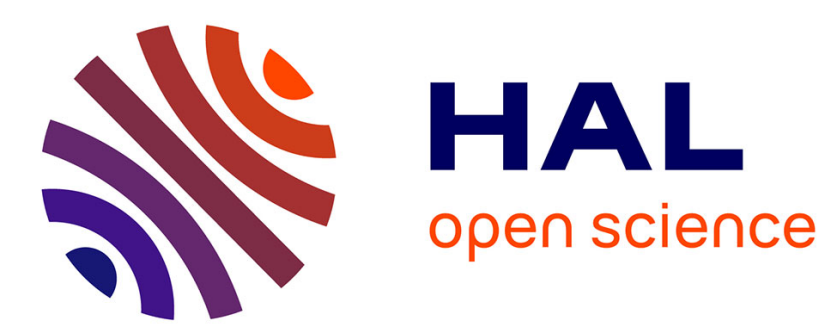

\title{
Capacitive Impedance for Following In-Situ Grafting Kinetics of Diazonium Salts
}

\author{
Viacheslav Shkirskiy, Eric Levillain, Christelle Gautier
}

\section{To cite this version:}

Viacheslav Shkirskiy, Eric Levillain, Christelle Gautier. Capacitive Impedance for Following In-Situ Grafting Kinetics of Diazonium Salts. ChemPhysChem, 2021, 22 (11), pp.1074-1078. 10.1002/cphc.202100154 . hal-03432298

\section{HAL Id: hal-03432298 \\ https://univ-angers.hal.science/hal-03432298}

Submitted on 22 Nov 2021

HAL is a multi-disciplinary open access archive for the deposit and dissemination of scientific research documents, whether they are published or not. The documents may come from teaching and research institutions in France or abroad, or from public or private research centers.
L'archive ouverte pluridisciplinaire HAL, est destinée au dépôt et à la diffusion de documents scientifiques de niveau recherche, publiés ou non, émanant des établissements d'enseignement et de recherche français ou étrangers, des laboratoires publics ou privés. 


\title{
Capacitive impedance for following in-situ the grafting kinetics of diazonium salts
}

\author{
Viacheslav Shkirskiy ${ }^{*}$ Eric Levillain, Christelle Gautier ${ }^{*}$ \\ MOLTECH-Anjou, Université D’Angers, UMR CNRS 6200, 2 Boulevard Lavoisier, 49045, Angers, France \\ E-mails: slava.shkirskiy@gmail.com, christelle.gautier@univ-angers.fr
}

Supporting information for this article is given via a link at the end of the document.

\begin{abstract}
A new method to follow in-situ grafting kinetics of diazonium compounds, based on the imposing of small amplitude high frequency $\mathrm{AC}$ oscillations at grafting potential, is outlined. This enables the timeresolved measurements of capacitive impedance, concomitantly with the growth of the organic layer at the working electrode. The impedance values were quantitatively correlated with the ex-situ (from voltammograms) and in-situ (from quartz crystal microbalance) measured surface coverages, providing a validation of the new methodology. The versatility of the developed approach was demonstrated on the grafting via reduction of 4nitrobenzenediazonium on Au and glassy carbon (GC) substrates and via deposition of in-situ generated diazonium salts from 1aminoanthraquinone and 4-ferrocenylaniline on GC. The capacitive impedance measurements are simple, fast, and non-destructive, making it an appealing methodology for an exploration of grafting kinetics of a wide range of diazonium salts.
\end{abstract}

\section{Introduction}

The electrochemical grafting of diazonium salts has been recognized to be a powerful method for the modification of conductive interfaces ${ }^{[1-3]}$. The deposition mechanisms include the reduction of diazonium derivatives with the generation of active radical species, prone to form a covalent chemical bond with a conductive interface ${ }^{[4]}$. Due to the high reactivity of radical species, the electrochemical turnover is accompanied by the formation of side products (dimers, oligomers etc.) in the bulk solution ${ }^{[5,6]}$ that renders impossible the quantitative correlation between the electrical charge and the amount of grafted species. Depending on the structure of the diazonium involved and the reaction time, faradaic efficiency ranging from 10 to $90 \%$ has been obtained on Au substrate ${ }^{[7]}$. In this regard, in the last decade a range of surface sensitive analytical methods has been developed to follow in-situ locally (ellipsometry ${ }^{[8]}$ and reflective microscopy ${ }^{[9]}$ ) and globally (quartz crystal microbalance - QCM ${ }^{[7,10,11]}$ ) grafting kinetics. In this work, a novel in-situ approach, based on the measurements of the capacitive response of deposited layers by means of electrochemical impedance spectroscopy (EIS), is proposed.

The EIS is a well-known technique often used by the community of researchers working on surface modification by reduction of diazonium cations and is commonly applied to the characterization of blocking properties of grafted layers ${ }^{[7,12]}$. The analysis, performed ex-situ, requires the addition of a redox mediator allowing the estimation of charge-transfer kinetics on deposited layers at low frequencies. In contrast to that, we suggest using an in-situ capacitive response of deposited layers at high $\mathrm{AC}$ frequency that can be performed without addition of any electrochemical mediator, simultaneously with the functionalization of the working electrode. With similar approach, the thickness of $\mathrm{ZrO}_{2}{ }^{[13]}, \mathrm{Al}_{2} \mathrm{O}_{3}{ }^{[14]}, \mathrm{Cr}_{2} \mathrm{O}_{3}{ }^{[14]}, \mathrm{Nb}_{2} \mathrm{O}_{5}{ }^{[15]}$ and $\mathrm{Fe}_{2} \mathrm{O}_{3}{ }^{[16]}$ films was quantified and correlated with ex-situ XPS ${ }^{[13,16]}$ and in-situ reflective microscopy ${ }^{[16]}$ measurements in the range of 2 $20 \mathrm{~nm}$, which is relevant for corrosion applications. The key aspect of EIS procedures was the data processing. The constant phase element (CPE) behavior of the films was extrapolated to the capacitive response $(C)$ at infinite frequency $\left(C_{\infty}\right)$ in Cole-Cole coordinates (corrected from the electrolyte resistance $\left.R_{e}\right)^{[17,18] \text { : }}$

$$
C(f)=1 / 2 \pi j f\left[Z(f)-R_{e}\right] \text {, }
$$

where $f$ is the frequency, $j=\sqrt{-1}$ and $Z$ is the measured impedance. With a known value of electrical permittivity $(\varepsilon)$, the thickness of the oxide layer $(\delta)$ were obtained from Eq. $2^{[13,16]}$.

$$
\delta={ }^{\varepsilon \varepsilon_{0}} / C_{\infty} \text {. }
$$

In principle, this approach is not restricted to the nature of the film and can be directly translated to the grafting of diazonium salts.

The goal of the present work is to explore the utility of capacitive measurements for the in-situ estimation of grafted layers surface coverages. The 4-nitrobenzenediazonium (NBD) and in-situ generated diazonium compounds obtained from 1aminoanthraquinone (AAQ) and 4-ferrocenylaniline (APhFc) are used as model systems on GC and Au substrates. The methodology is validated through comparison with surface coverages of electrochemically active groups measured ex-situ (from voltammograms) and in-situ (from QCM). The practical aspects of the implementation of capacitive measurements are discussed.

\section{Results and Discussion}

\section{Capacitive impedance of deposited layers.}

The NB films of different surface coverages were formed by chronoamperometry. Herein, all experiments were carried out at a fixed potential to avoid any variations in the capacitance of the double layer on GC and possible modifications of the structure of the deposited layers. Then, the functionalized working electrodes were studied by in-situ EIS directly in solutions with diazonium salts and by ex-situ cyclic voltammetry in $0.1 \mathrm{M} \mathrm{KOH}$ aqueous solutions.

Fig. 1a shows the impedance spectra in Nyquist coordinates of NB layers formed after 1, 10 and 90 min of NBD reduction at the constant potential of $-0.4 \mathrm{~V}$, on GC. The spectra were measured in-situ right after the chronoamperometry, keeping the potential at $-0.4 \mathrm{~V}$. The frequency range of $10 \mathrm{kHz}-100 \mathrm{~Hz}$ was chosen to be sensitive to a capacitive response of the formed layer and to provide fast data acquisition (ca. $3 \mathrm{~s}$ ). All curves in Fig. 1a have a similar shape. They start in the proximity of $15 \Omega \times \mathrm{cm}^{2}$ on real impedance axis at $10 \mathrm{kHz}$, rise linearly with the slope of ca. $90^{\circ}$ up to ca. $464 \mathrm{~Hz}$ then the slope decreases at lower frequencies down to $100 \mathrm{~Hz}$. The observed shape is typical of a capacitive response with the slope decrease possibly due to the contribution of faradaic discharge of the diazonium salt at lower frequencies. Overall, the impedance increases with the polarization time used for layer formation. 
(a)

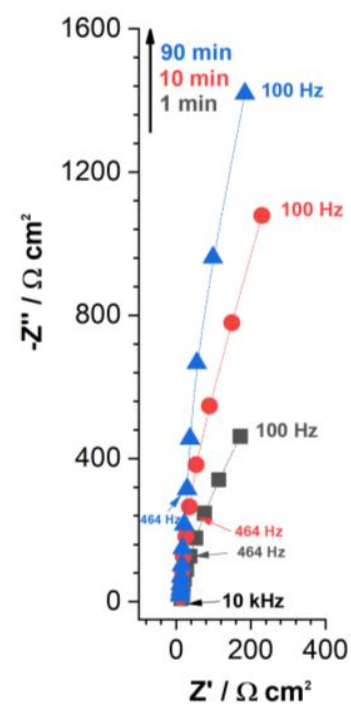

(b)

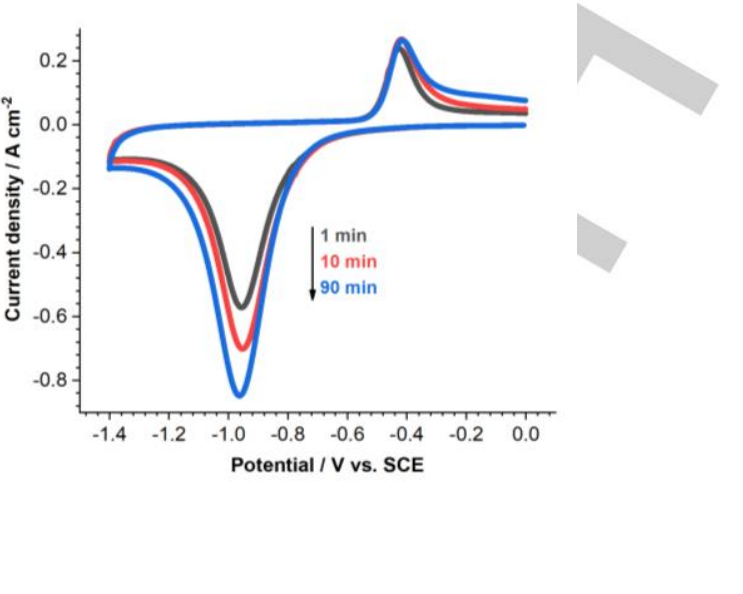

Fig. 1 (a) EIS spectra in Nyquist coordinates of NB layers on GC after grafting at $-0.4 \mathrm{~V}$ vs. $\mathrm{Ag}_{\mathrm{AgNO}}$ in $0.1 \mathrm{M} \mathrm{TBAPF}_{6} 1 \mathrm{mM} \mathrm{NBD} \mathrm{MeCN}$ solution for $1 \mathrm{~min}$ (grey), $10 \mathrm{~min}$ (red) and $90 \mathrm{~min}$ (blue). (b) Cyclic voltammograms recorded on NB layers in a deaerated $0.1 \mathrm{M} \mathrm{KOH}$ aqueous solution. The potential sweep starts at $0 \mathrm{~V}$, progresses towards $-1.4 \mathrm{~V}$ and returns back to the initial potential at a ramp speed of $100 \mathrm{mV} / \mathrm{s}$.

After the EIS experiments, the surface coverages of NB layers were measured by ex-situ cyclic voltammetry experiments in a deaerated $0.1 \mathrm{M} \mathrm{KOH}$ aqueous solution (Fig. 1b). In all three curves, cathodic current peaks at ca. $-0.9 \mathrm{~V}$ vs. SCE on the onward sweeps and anodic current peaks on the forward sweeps at ca. $-0.45 \mathrm{~V}$ vs. SCE. The cathodic peak is conventionally attributed to the sum of two reactions: the irreversible reduction of nitrophenyl $\left(\mathrm{Ar}-\mathrm{NO}_{2}\right)$ and hydroxyaminophenyl $(\mathrm{Ar}-\mathrm{NHOH})$ groups to aminophenyl $\left(\mathrm{Ar}-\mathrm{NH}_{2}\right)$ groups. On the return scan, the reversible oxidation of Ar- $\mathrm{NHOH}$ to nitrosophenyl (Ar-NO) groups is observed ${ }^{[2,19]}$. The amplitudes of both peaks increase with the grafting time that is coherent with the increase of impedance values in Fig. 1a. Note that the peaks positions vary less than 15 $\mathrm{mV}$. This indicates insignificant contribution of layer resistivity on faradaic discharge of grafted NB, suggesting that all immobilized groups are electrochemically active ${ }^{[20,21]}$.

Surface coverages $(\Pi)$ of NB layers were calculated by summing the charges for the irreversible reduction of $\mathrm{Ar}-\mathrm{NO}_{2}$ and the charge of $\mathrm{Ar}-\mathrm{NHOH}$ reoxidation, assuming a 6 -electron transfer for each nitro group ${ }^{[19]}$ (details in SI-1). Curve 1 in Fig. 2 shows the absolute values of impedance $(|Z|)$ plotted as a function of $\Gamma$ for grafting times between $1 \mathrm{~min}$ and $90 \mathrm{~min}$.

Importantly, there is a linear relationship between $|Z|$ and $\Gamma$, suggesting a direct link between the capacitive response of the layer and surface coverage of electroactive groups. To verify that this relationship is not specific to the NB layer, $A Q$ and $\mathrm{PhFc}$ groups were grafted on $\mathrm{GC}$ at $-0.4 \mathrm{~V}$ vs. $\mathrm{Ag} / \mathrm{AgNO}_{3}$ from the insitu generated diazonium salts. Similarly to NB layers, the impedances of $A Q$ and $P h F c$ layers were measured in-situ and reported versus the surface coverages obtained from voltammograms recorded ex-situ on the layers (see Fig. S1 and Fig. S2 in Supplementary Information - SI for EIS spectra in Nyquist coordinates and cyclic voltammograms recorded on $A Q$ and $\mathrm{PhFc}$ layers respectively). Curves 2 and 3 in Fig. 2 (for $A Q$ and $\mathrm{PhFc}$ films respectively) demonstrate a linear relationship between $|Z|$ and $\Gamma$ for $\mathrm{AQ}$ and $\mathrm{PhFc}$ layers as well. The goodness of the linear fit of $|Z|$ vs. $\Gamma$ was estimated as a function of $A C$ frequency (Fig. S3 in $\mathrm{SI}$ ). For all three compounds, the best correlation $\left(R^{2}=97-99 \%\right)$ was found at $10 \mathrm{kHz}$. The values of $R^{2}$ decreased with the frequency down to ca. $92 \%$, possibly due to the interference of faradaic discharge of present in the solution diazonium salts at lower frequencies. Since only a measurement at a single frequency is required for $|Z|$ and $\Gamma$ correlation, the small amplitude oscillating voltage at $10 \mathrm{kHz}$ can be imposed

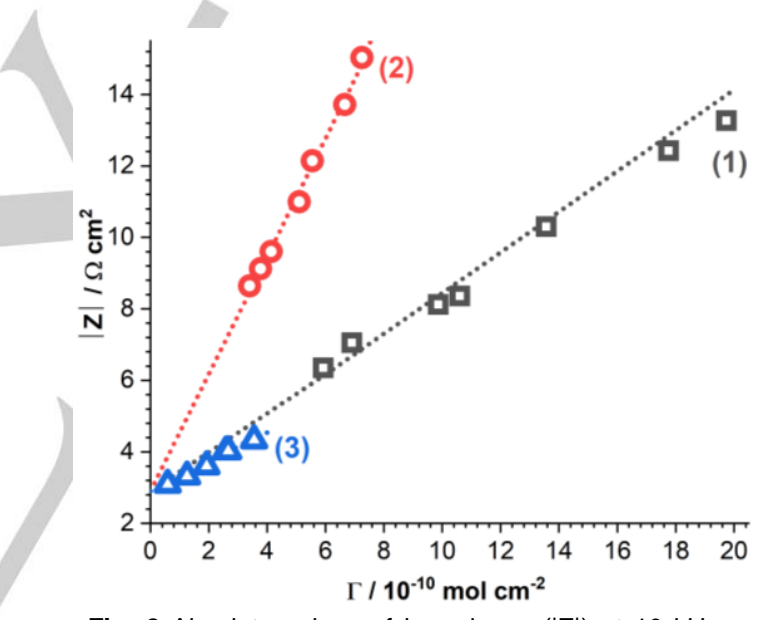

Fig. 2 Absolute values of impedance (|Z|) at $10 \mathrm{kHz}$ vs. surface coverage for (1) NB, (2) AQ and (3) PhFc layers for 1 min - 90 min grafting times. NB layers were grafted from a $0.1 \mathrm{mM}$ solution of NBD compound. The $A Q$ and $P h F c$ layers were grafted from the $1 \mathrm{mM}$ solutions of the corresponding amine derivatives with in-situ generation of diazonium salts. The resistance of electrolyte was subtracted from |Z|. The dotted lines represent the fit with linear least squares.

around the grafting potential for following in real time the surface coverage (vide infra).

All three curves intercept $|Z|$ axis $(\Gamma=0)$ at $2.9 \pm 0.2$ $\Omega \times \mathrm{cm}^{2}$, which should reflect the capacitive response of a nongrafted GC interface. The absolute values of $\Gamma$ after $90 \mathrm{~min}$ of grafting decrease in order of NB $\left(20 \times 10^{-10} \mathrm{~mol} \mathrm{~cm}^{-2}\right) A Q\left(7 \times 10^{-}\right.$ $\left.{ }_{10} \mathrm{~mol} \mathrm{~cm}^{-2}\right)$ and PhFc $\left(4 \times 10^{-10} \mathrm{~mol} \mathrm{~cm}^{-2}\right)$ in Fig. 2. Note that based on this, the kinetics of grafting cannot be quantitatively compared due to a diverse range of grafting conditions. Slope values of $|Z|$ vs. $\Gamma$ decrease in order of $A Q\left(17 \Omega \times \mathrm{cm}^{4} / \mathrm{nmol}\right) \gg$ NB $\left(5 \Omega \times \mathrm{cm}^{4} / \mathrm{nmol}\right) \approx \operatorname{PhFc}\left(4 \Omega \times \mathrm{cm}^{4} / \mathrm{nmol}\right)$. Close slope values for $\mathrm{NB}$ and $\mathrm{PhFc}$ layers suggest similar structure of these layers in contrast to $A Q$ layers, probably due to the drastic differences in the molecular structure of phenyl and anthraquinone derivatives.

Correlation between capacitive impedance and QCM measurements. 
The impedance measurements at a single frequency of 10 $\mathrm{kHz}$ were recorded in-situ in real time during the electrochemical reduction of NBD. In concrete terms, an oscillating potential with

(a)

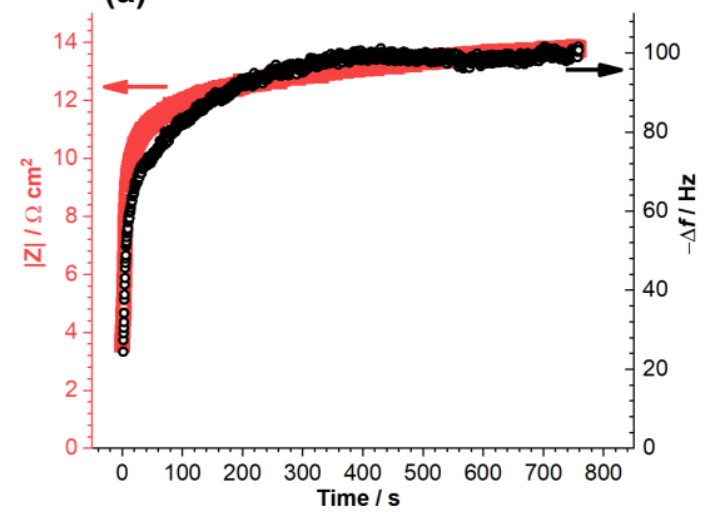

(b)

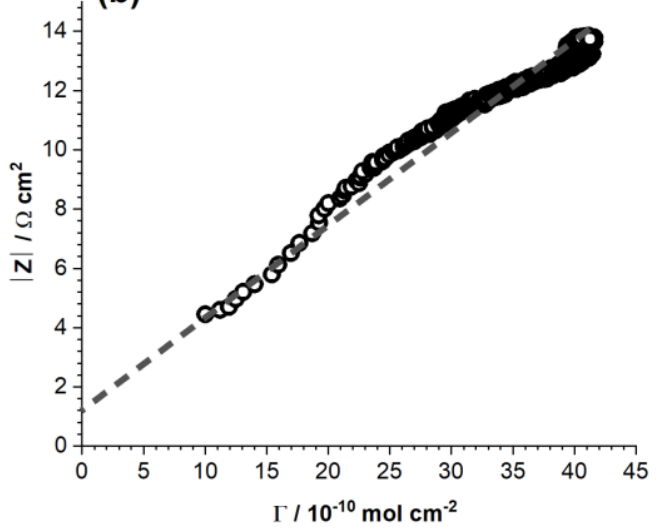

Fig. 3 (a) Simultaneous recordings of the frequency (- $\Delta f)$ of Au covered quartz resonator (right axis) and the capacitive measurements at 10 $\mathrm{kHz}$ of the Au interface (left axis) during grafting at $-0.4 \mathrm{~V}$ vs. Ag/AgNO 3 in $1 \mathrm{mM} \mathrm{NBD} 0.1 \mathrm{M} \mathrm{TBAPF} 6 \mathrm{MeCN}$ solution. A decrease of $1 \mathrm{~Hz}$ corresponds to an increase of $1 \mathrm{ng}$. The resistance of electrolyte was subtracted from $|Z|$. The frequency change in (a) was converted to $\Gamma$, and $|Z|$ vs. $\Gamma$ was plotted in (b). The dash line is shown for the visual reference.

frequency of $10 \mathrm{kHz}$ and $30 \mathrm{mV}$ peak-to-peak amplitude was imposed around a grafting potential of $-0.4 \mathrm{~V}$ vs. $\mathrm{Ag} / \mathrm{AgNO}_{3}$ to modify a Au coated quartz crystal. At the same time, mass variations related to the formation of the NB layer were recorded with the QCM, connected to the same potentiostat to guarantee identical time scales of EIS and QCM. These two independent measurements are compared in Fig. 3 . Both curves $(|Z|$ and $-\Delta f$ vs. time) show similar trends: initial drastic increase during first 20 - $30 \mathrm{~s}$ followed by transition to a steady-state behavior after 700 $800 \mathrm{~s}$ of grafting with $-\Delta f$ approaching to $100 \mathrm{~Hz}$ and $|Z|$ to 13 $\Omega \times \mathrm{cm}^{2}$. The $-\Delta f$ curve starts at $20 \mathrm{~Hz}$ suggesting an instantaneous grafting of $\mathrm{PhNO}_{2}$ occurring before data collection started. The observed shape of $-\Delta f$ curve has been numerously reported in the literature ${ }^{[7,10,11]}$ and is generally attributed to the fast deposition of a NB monolayer followed by the progressive slower growth of multilayers. The value of grafting rate at $t=0 \mathrm{~s}$ was estimated

$0.7 \mathrm{nmol} \mathrm{s}^{-1} \mathrm{~cm}^{-2}$ from EQCM measurement in this work that is in a good agreement with the previously reported values of $0.6-1.7$ $\mathrm{nmol} \mathrm{s} \mathrm{sm}^{-2}$ found under similar conditions ${ }^{[10]}$. The slight decrease of $-\Delta f$ curve by ca. $5 \mathrm{~Hz}$ after $400 \mathrm{~s}$ is within the expected range of random fluctuations of the background signal, reported for QCM experiments ${ }^{[22]}$

Data in Fig. 3a were replotted in Fig. $3 b$ as $|Z|$ vs. $\Gamma$ for the quantitative cross correlation between the in-situ impedance and QCM data. These data can be approximated by a straight line with an intercept $(\Gamma=0)$ of $1.2 \Omega \times \mathrm{cm}^{2}$ and a slope of $4 \Omega \times \mathrm{cm}^{4} / \mathrm{nmol}$. Importantly, this slope is in a reasonable agreement with the data for NB layer on GC in Fig. 2 (curve 1), showing that the slope of $|Z|$ vs. $\Gamma$ rather depends on the grafted compound and is not related to the substrate properties. At the same time, the intercepts

Fig. $3 b$ and Fig. 2 differ significantly due to the difference in properties of electrical double layers of non-grafted $A u$ and GC substrates.

Practicalities of capacitive measurements.

The greatest advantage of the surface coverage estimation from capacitive measurements is that this approach can be easily integrated to existing grafting procedures without any modification of experimental setup. Small amplitude high frequency potential oscillations can be readily superimposed on DC potential via already implemented software routine for the majority of commercially available potentiostats, making it cheap and accessible for a wide range of users. The previous research on the thickness estimation of passive layers in corrosion required replotting of data in Cole-Cole coordinates for the elimination of CPE behavior using Eq. $1^{[13,16]}$. In this work, we showed that capacitive impedance at $10 \mathrm{kHz}$ of grafted layers can be directly linked to the surface coverages without supplementary data processing, establishing a quantitative footing of the new methodology for in-situ monitoring the grafting from diazoniums. Finally, it is worth commenting that conventional EIS procedures collect an averaged response over the whole interface, ignoring possible local variations in the thickness of the grafted layers ${ }^{[23]}$. One interesting avenue for the future work will be to explore the utility of this methodology in localized capacitive measurements, for example in scanning ion conductance microscopy configuration ${ }^{[24]}$.

\section{Conclusion}

Application of small amplitude high frequency potential oscillations at the reduction potential of diazonium salts enables in-situ measurements of the capacitive impedance that is linearly related to the surface coverage of deposited species. This concept was validated via correlations with surface coverages estimated from ex-situ measured voltammograms after grafting of NBD and in-situ generated diazonium salts from AAQ and APhFc on GC. Quantitative comparison between QCM and capacitive measurements at $10 \mathrm{kHz}$ during grafting of NBD on Au showed identical outcome of these two approaches, thus showing that this method can be generalized not only to any type of diazonium, but also to any electrode material. Being simplistic and robust, the capacitive measurements provide a promising avenue for future works on investigation of grafting kinetics.

\section{Experimental Section}

Materials and reagents

NBD (Sigma-Aldrich), AAQ (Alfa Aesar), tetrabutylammonium hexafluorophosphate (TBAPF 6 - Sigma-Aldrich), acetonitrile (MeCN HPLC grade, Carlo Erba), tert-Butyl nitrite (tBuONO - Sigma-Aldrich) and 
potassium hydroxide ( $\mathrm{KOH}$ - Sigma-Aldrich) were used as received. MilliQ water $(18 \mathrm{M} \Omega \times \mathrm{cm})$ was used for aqueous solutions. A circular $\mathrm{GC}$ electrode was supplied by Bioanalytical Systems Inc. (Model MF-2012 with a surface area of $0.07 \mathrm{~cm}^{2}$ ). The APhFc compound has been synthetized by a twostep procedure already described in the literature ${ }^{[25,26]}$.

Layer deposition and its characterization

Prior to each experiment, the surface of GC was polished with a $0.04 \mu \mathrm{m} \mathrm{Al} \mathrm{O}_{3}$ slurry (PRESI), sonicated in water for $2 \mathrm{~min}$ and rinsed successively with water and MeCN. A BioLogic potentiostat (VSP model with 4 channels) was employed to carry out all electrochemical experiments. Electrochemical grafting was performed in a 3-electrode cell with $5 \mathrm{ml}$ of $0.1 \mathrm{M} \mathrm{TBAPF}_{6} \mathrm{MeCN}$ stagnant solution with the addition of 0.1 $\mathrm{mM}$ or $1 \mathrm{mM}$ of the desired compound at room temperature. A Pt rod counter electrode was used throughout this work. $\mathrm{A} \mathrm{Ag} / \mathrm{AgNO}_{3}(0.01 \mathrm{M}$ in $0.1 \mathrm{M} \mathrm{TBAPF}_{6} \mathrm{MeCN}$ ) was used in $\mathrm{MeCN}$ solutions and a saturated calomel electrode (SCE) was used in $\mathrm{KOH}$ aqueous solutions as reference electrodes. All electrode potentials are quoted vs. corresponding reference electrodes.

To initiate grafting, the potential was stepped from the open circuit value to $-0.4 \mathrm{~V}$ vs. $\mathrm{Ag} / \mathrm{AgNO}_{3}$ and hold for $1 \mathrm{~min}-90 \mathrm{~min}$. In case of $\mathrm{AAQ}$ and APhFc compounds, 5 equivalents of tBuONO were added into solutions and stirred for 10 min before imposing $-0.4 \mathrm{~V}$ vs. $\mathrm{Ag} / \mathrm{AgNO}_{3}$ for the in-situ generation of diazonium salts from amines as described in literature[27]. Immediately after the layer formation, the impedance measurements were employed in the same cell configuration at $-0.4 \mathrm{~V}$ vs $\mathrm{Ag} / \mathrm{AgNO}_{3}$ with a $30 \mathrm{mV}$ peak-to-peak amplitude from $10 \mathrm{kHz}$ to $100 \mathrm{~Hz}$ with 6 points per decade. Then the GC electrodes were sonicated for 2 $\mathrm{min}$ in MeCN solution. The surface coverage of electroactive groups was estimated by cyclic voltammetry at $100 \mathrm{mV} / \mathrm{s}$ in a deaerated $0.1 \mathrm{M} \mathrm{KOH}$ (for nitrobenzene (NB) and anthraquinone (AQ) layers) or in 0.1 M TBAPF MeCN (for ferrocenylbenzene (PhFc) layers) solutions.

QCM

A Quartz Crystal Analyser QCA922, connected to the BioLogic potentiostat, was employed to follow the change of mass during grafting of NBD on an AT-cut $9 \mathrm{MHz}$ Au coated quartz crystal resonator $\left(0.2 \mathrm{~cm}^{2}\right)$ Details of EQCM setup can be found elsewhere ${ }^{[12,22]}$. Briefly, the EQCM cell was sealed and placed vertically in a 3-electrode electrochemical cell $(22 \mathrm{ml})$ with $\mathrm{Ag} / \mathrm{AgNO}_{3}$ reference and $\mathrm{Pt}$ counter electrodes. The $\mathrm{Au}$ electrode was held at a constant potential of $+0.5 \mathrm{~V} \mathrm{vs}$. $\mathrm{Ag} / \mathrm{AgNO}_{3}$ in 0.1 $M$ TBAPF $_{6}$ MeCN electrolyte $(22 \mathrm{ml})$ until the stabilization of the crystal resonator signal. Then, a concentrated solution of NBD was injected under stirring to match the final concentration of $1 \mathrm{mM} \mathrm{NBD}$. After $3 \mathrm{~min}$, the agitation was stopped and the potential was stepped to $-0.4 \mathrm{~V}$ vs. $\mathrm{Ag} / \mathrm{AgNO}_{3}$ to initiate grafting. An AC frequency of $10 \mathrm{kHz}$ and $30 \mathrm{mV}$ peakto-peak amplitude was imposed around grafting potential to follow capacitive impedance during the layer formation. The Ohmic drop was measured before and after the experiment to ensure that the solution volume did not change and it was manually subtracted from all capacitive measurements.

\section{Acknowledgements}

The authors acknowledge the LUMOMAT funding program for a post-doctoral fellowship.

Keywords: diazonium grafting $•$ EIS $•$ QCM $•$ kinetics

[1] D. Hetemi, V. Noël, J. Pinson, Biosensors 2020, 10, 4

[2] D. Bélanger, J. Pinson, Chem. Soc. Rev. 2011, 40, 3995-4048.

[3] P. Hapiot, C. Lagrost, Y. R. Leroux, Curr. Opin. Electrochem. 2018, P. Hapiot, C. Lagrost, Y. R. Leroux, Curr. Opin. Electrochem. 2018,
7, 103-108.

[4] M. Delamar, R. Hitmi, J. Pinson, J. M. Savéant, J. Am. Chem. Soc. 1992, 114, 5883-5884.

[5] L. Pichereau, I. López, M. Cesbron, S. Dabos-Seignon, C. Gautier, T. Breton, Chem. Commun. 2019, 55, 455-457.

[6] P. Doppelt, G. Hallais, J. Pinson, F. Podvorica, S. Verneyre, Chem. Mater. 2007, 19, 4570-4575.

[7] A. Laforgue, T. Addou, D. Bélanger, Langmuir 2005, 21, 68556865.

[8] M. Busson, A. Berisha, C. Combellas, F. Kanoufi, J. Pinson, Chem. Commun. 2011, 47, 12631-12633.

[9] S. Munteanu, J. P. Roger, Y. Fedala, F. Amiot, C. Combellas, G. Tessier, F. Kanoufi, Faraday Discuss. 2013, 164, 241-258.

[10] S. Bouden, J. Pinson, C. Vautrin-UI, Electrochem. commun. 2017 $81,120-123$

[11] J. Haccoun, C. Vautrin-UI, A. Chaussé, A. Adenier, Prog. Org.
Coatings 2008, 63, 18-24.

[12] T. Breton, D. Bélanger, Langmuir 2008, 24, 8711-8718.

[13] M. Benoit, C. Bataillon, B. Gwinner, F. Miserque, M. E. Orazem, C. M. Sánchez-Sánchez, B. Tribollet, V. Vivier, Electrochim. Acta 2016 201, 340-347.

[14] B. Hirschorn, M. E. Orazem, B. Tribollet, V. Vivier, I. Frateur, M Musiani, J. Electrochem. Soc. 2010, 157, C452-C457.

[15] B. Hirschorn, M. E. Orazem, B. Tribollet, V. Vivier, I. Frateur, M. Musiani, Electrochim. Acta 2010, 55, 6218-6227.

[16] S. Chakri, A. N. Patel, I. Frateur, F. Kanoufi, E. M. M. Sutter, T. T. M. Tran, B. Tribollet, V. Vivier, Anal. Chem. 2017, 89, 5303-5310.

M. E. Orazem, N. Pébère, B. Tribollet, J. Electrochem. Soc. 2006,

153, B129-B139.

A. K. Jonscher, Electrochim. Acta 1990, 35, 1595-1600.

[19] M. Kullapere, M. Marandi, L. Matisen, F. Mirkhalaf, A. E. Carvalho,

G. Maia, V. Sammelselg, K. Tammeveski, J. Solid State

Electrochem. 2012, 16, 569-578.

[20] P. A. Brooksby, A. J. Downard, Langmuir 2004, 20, 5038-5045.

[21] P. A. Brooksby, A. J. Downard, J. Phys. Chem. B 2005, 109, 87918798.

[22] C. Gautier, O. Alévêque, F. Seladji, M. Dias, T. Breton, E. Levillain, Electrochem. commun. 2010, 12, 79-82.

[23] J. K. Kariuki, M. T. McDermott, Langmuir 1999, 15, 6534-6540.

[24] V. Shkirskiy, M. Kang, I. J. McPherson, C. L. Bentley, O. J. Wahab, E. Daviddi, A. W. Colburn, P. R. Unwin, Anal. Chem. 2020, 92 , 12509-12517.

H. Ping, K. Q. Zhao, H. B. Xu, Molecules 2001, 6, M249.

[26] H. Ping, K. Q. Zhao, H. B. Xu, Molecules 2001, 6, M250.

[27] S. Baranton, D. Bélanger, Electrochim. Acta 2008, 53, 6961-6967. 


\section{Table of Contents}

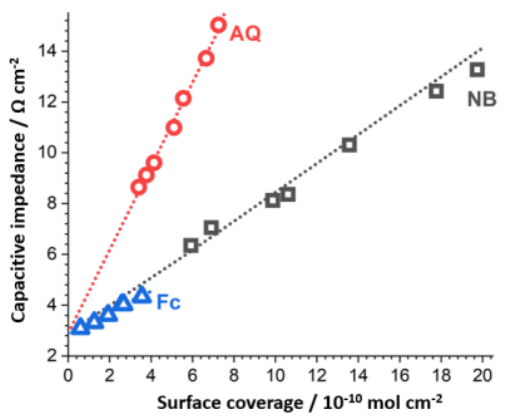

Capacitive response of deposited layers correlate quantitatively with the surface coverages of grafted diazonium salts. This opens an avenue for the in-situ in real time robust measurements of grafting kinetics. The new method was validated through comparison with in-situ quartz microbalance and ex-situ cycling voltammetry measurements on glassy carbon and gold substrates with a variety of grafted species. 